\title{
Corrosion Behaviour of AGR Simulated Fuels - Evolution of the Fuel Surface
}

\author{
N. Rauff-Nisthar ${ }^{\mathrm{a}}$, C. Boxall ${ }^{\mathrm{a}}$, I. Farnan ${ }^{\mathrm{c}}, \mathrm{Z}_{\text {. Hiezl }}^{\mathrm{b}}$, W. Lee ${ }^{\mathrm{b}}$, C. Perkins ${ }^{\mathrm{d}}$ and R. \\ Wilbraham ${ }^{\mathrm{a}}$, \\ a Engineering Department, Lancaster University, Lancaster LA1 4YR, UK, \\ ${ }^{\mathrm{b}}$ Department of Earth Sciences, University of Cambridge, Downing Street Cambridge \\ CB2 3EQ, UK, \\ ${ }^{\mathrm{c}}$ Department of Materials, Imperial College London, London SW7 2BP, UK, \\ ${ }^{\mathrm{d}}$ National Nuclear Laboratory, Building A709, Springfields Site, Salwick, Lancashire \\ PR4 0XJ, UK
}

We have prepared a range of Advanced Gas-cooled Reactor (AGR) SIMFUELs at a range of simulated burn-ups and, using Raman spectroscopy, have studied the effect of the SIMFUEL dopants on the $\mathrm{UO}_{2}$ crystal structure. We have also studied the effect of exposure to hydrogen peroxide solutions on the SIMFUEL surface. The intensity of the fundamental U-O stretch $\left(445 \mathrm{~cm}^{-1}\right)$ decreases as the amount of dopant increases in each SIMFUEL burn-up composition. A simultaneous increase in the lattice damage $\left(500-700 \mathrm{~cm}^{-1}\right)$ peak is observed as the $\mathrm{UO}_{2}$ cubic fluorite lattice structure becomes more distressed and moves towards a tetragonal structure. Exposure to $100 \mu \mathrm{mol} \mathrm{dm}{ }^{-3} \mathrm{H}_{2} \mathrm{O}_{2}$ further decreases the fundamental U-O stretch and increases the lattice damage peak, suggesting that additional point defects are established as the concentration of interstitial oxygen is increased in the lattice via the $\mathrm{H}_{2} \mathrm{O}_{2}$-induced corrosion of the SIMFUEL.

\section{Introduction}

The direct disposal of spent nuclear fuel into a geological repository is part of the nuclear waste policy of several mature nuclear states (USA, Sweden, Spain and Finland are prominent examples). The vast majority of this fuel is from light-water moderated reactors (LWR) and a significant amount of research has been carried out to support the direct disposal concept in terms of the physical and aqueous durability of the container, the cladding and the irradiated $\mathrm{UO}_{2}$-based fuel. In the UK, the vast proportion of spent nuclear fuel (SNF) is from indigenous Advanced Gas-cooled Reactors (AGRs). AGRs, whilst also using $\mathrm{UO}_{2}$-based fuel, employ $\mathrm{CO}_{2}$ as coolant and are graphite moderated. Further, the fuel assembly cladding is comprised of 20/25/Nb stainless steel (20\% Cr, $25 \% \mathrm{Ni}$ ) rather than zircalloy as is the case in Pressurised Water Reactors (PWRs). Consequently, AGR fuel has unique characteristics that need to be evaluated in order to satisfy safety case requirements before it can be disposed of in a geological repository.

It is expected that, at some point after repository closure, the disposal canisters within which the SNF is sealed will fail, allowing for ingress of groundwater. This may come into contact with the $20 / 25 / \mathrm{Nb}$ cladding and the spent $\mathrm{UO}_{2}$ fuel pellets, initiating corrosion processes on either or both. At this failure point, anticipated as being many 
thousands of years into the future, many of the fission products will have decayed away, as will the associated $\beta / \gamma$ radiation field, leaving an $\alpha$ field derived from long-lived $\alpha$ emitting actinides. Alpha radiolysis of the invading groundwater as it comes into contact with the $\mathrm{UO}_{2}$ fuel pin will generate hydrogen peroxide as one of several end species (1).

Hydrogen peroxide concentrations in the near-field are expected to lie somewhere between $100 \mu \mathrm{mol} \mathrm{dm}{ }^{-3}$ and $1 \mathrm{mmol} \mathrm{dm}^{-3}$ (2). This locally oxidising environment may convert U(IV) to U(VI), so allowing $U$ to pass into solution, with the possibility of reprecipitation of oxidized $\mathrm{U}(\mathrm{VI})$ back onto the fuel pellet surface, generating secondary mineral phases such as schoepite. The peroxide minerals studtite $\left(\mathrm{UO}_{2}\right) \mathrm{O}_{2}\left(\mathrm{H}_{2} \mathrm{O}\right)_{4}$ and metastudtite $\left(\mathrm{UO}_{2}\right) \mathrm{O}_{2}\left(\mathrm{H}_{2} \mathrm{O}\right)$ are stable in $\mathrm{H}_{2} \mathrm{O}_{2}$-bearing environments even at low $\left[\mathrm{H}_{2} \mathrm{O}_{2}\right]$. Studtites have recently been found in Chernobyl lavas (3), formation possibly occurring at the expense of more common transformation phases. As such, studitite layers may form a barrier for retarding SNF corrosion and could retain radionuclides either within their structure or by surface adsorption. Whether more or less corrosion obtains in the presence of the studtites is a generic research question for all $\mathrm{UO}_{2}$-based SNF, not just AGR SNF, which needs to be explored.

As recently elucidated and reviewed by $\mathrm{He}$ et al. (4), the process of fuel corrosion in the presence of $\mathrm{H}_{2} \mathrm{O}_{2}$ is complicated by the hyperstoichiometric behaviour of $\mathrm{UO}_{2}$. As $\mathrm{UO}_{2}$ moves towards hyperstoichiometry through the peroxide-driven oxidation of U(IV) sites, $\mathrm{U}(\mathrm{V}) / \mathrm{U}(\mathrm{IV})$ donor-acceptor sites may be generated, which in turn catalyse the reduction of $\mathrm{H}_{2} \mathrm{O}_{2}$ (4). The balance of electrons in this process is provided by coupled chemical/electrochemical oxidation of $\mathrm{U}(\mathrm{IV})$ to $\mathrm{U}(\mathrm{V})$, catalytically further accelerating the rate of peroxide reduction, and (similarly coupled) $\mathrm{U}(\mathrm{IV})$ oxidation to $\mathrm{U}(\mathrm{VI})$ with its release to solution as $\mathrm{UO}_{2}{ }^{2+}$. Generation of $\mathrm{UO}_{2}{ }^{2+}$ in the presence of $\mathrm{H}_{2} \mathrm{O}_{2}$ may result in the formation of studtite/metastudtite (4). These processes are illustrated in Figure 1.

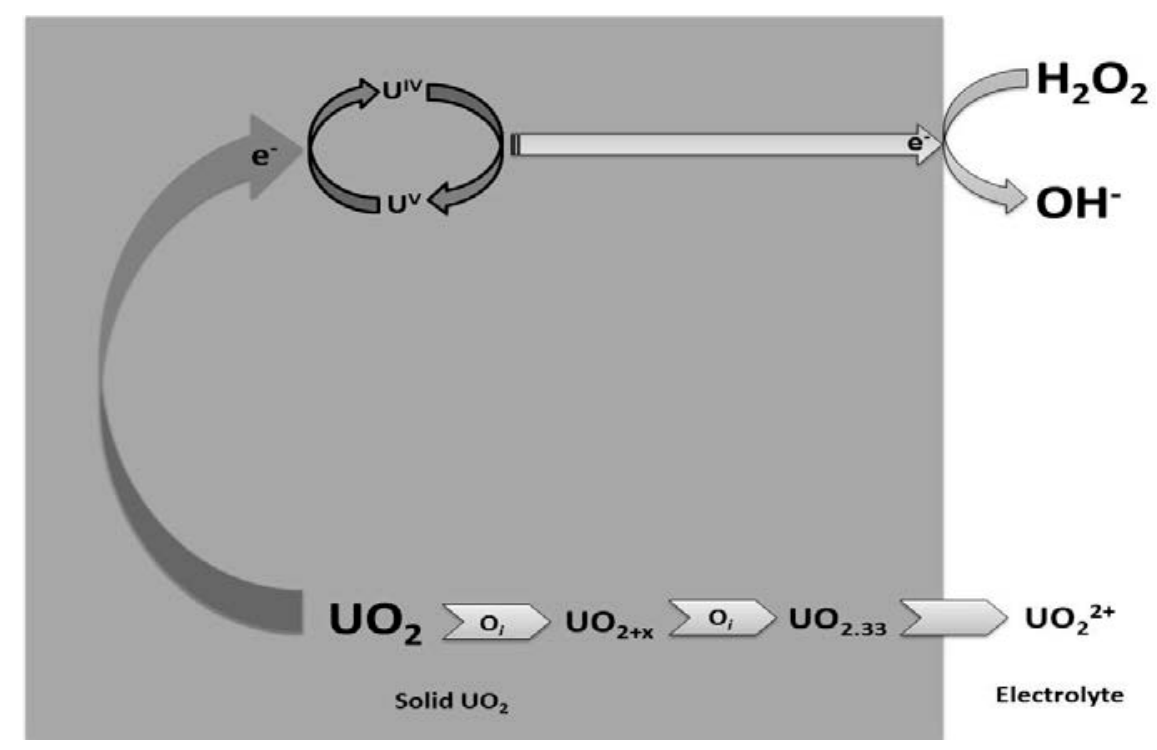

Figure 1 Schematic representing mechanism of $\mathrm{UO}_{2}$ dissolution in the presence of $\mathrm{H}_{2} \mathrm{O}_{2}$

Here we describe for the first time preliminary Raman microscope studies of a novel AGR simulated fuel (SIMFUEL) as a precursor to future long term AGR fuel corrosion studies. We have characterised samples representative of two different burn-ups (25 
$\mathrm{GWd} / \mathrm{tU}$ and $43 \mathrm{GWd} / \mathrm{tU})$. Such samples were also exposed briefly to $100 \mu \mathrm{mol} \mathrm{\textrm {dm } ^ { - 3 }}$ $\mathrm{H}_{2} \mathrm{O}_{2}$, in order to investigate secondary phase formation over short time scales.

\section{Experimental}

Pure $\mathrm{UO}_{2}$ pellets and SIMFUEL pellets simulating $25 \mathrm{GWd} / \mathrm{tU}$ and $43 \mathrm{GWd} / \mathrm{tU}$ burnup were fabricated at the UK National Nuclear Laboratory (Springfields, Preston, UK). SIMFUEL pellets were prepared by sintering powder precursors containing the dopant compositions given in Table I. Compositions were calculated using FISPIN nuclear inventory calculation code (developed by the National Nuclear Laboratory UK and distributed by AMEC (5)) and are representative of a fuel pellet that has aged for 100 years after removal from the reactor. Both the $\mathrm{UO}_{2}$ and SIMFUEL pellets were prepared by first formulating a $60 \mathrm{~g}$ blend of each composition. These were milled overnight with a $\mathrm{ZrO}_{2}$ milling medium. In order to pre-compact the powder into granulates, a pressure of $75 \mathrm{MPa}$ was applied. $0.2 \mathrm{wt}$. \% zinc stearate was added as the binder and the material was slowly mixed for 5 minutes using a rotary mixer. The granulates were then pressed into green pellets by applying a pressure of $400 \mathrm{MPa}$ using a uniaxial machine. All pellets were sintered at a heating rate of $5{ }^{\circ} \mathrm{C} / \mathrm{min}$ to $300{ }^{\circ} \mathrm{C}$, and then $15^{\circ} \mathrm{C} / \mathrm{min}$ to $1730{ }^{\circ} \mathrm{C}$. The sintering time was 300 minutes which was followed by cooling, with a cooling rate of $15{ }^{\circ} \mathrm{C} / \mathrm{min}$ until room temperature had been reached. The furnace (supplied by Cambridge Vacuum Engineering) atmosphere contained 99.5 vol\% $\mathrm{H}_{2}$ and 0.5 vol\% $\mathrm{CO}_{2}$. The finished pellets were cut into slices ranging from $\sim 1-3 \mathrm{~mm}$ thick using a Struers Accutom-2 precision cut-off machine with a Struers MOD13 diamond cut-off wheel.

As received sample slices were immersed in deionised water (Direct-Q 3 UV Millipore water purification system - Millipore, Watford, UK, resistivity $18.2 \mathrm{M} \Omega . \mathrm{cm}$ ) and $100 \mu \mathrm{mol} \mathrm{dm}{ }^{-3}$ hydrogen peroxide (Acros Organics, $\mathrm{H}_{2} \mathrm{O}_{2}$ for analysis, $35 \mathrm{wt}$ \% solution in water, stabilised) solutions for 1 hour. Each pellet was attached to a stainless steel rod using PTFE tape to ensure that only one side of the slice would be exposed to the solution. The slices were characterised before and after immersion by $785 \mathrm{~nm}$, microRaman spectroscopy (Voyage System, B\&W Tek, USA) using a laser power below 5 $\mathrm{mW}$ in order to avoid any thermal conversion of $\mathrm{UO}_{2}$ to $\mathrm{U}_{3} \mathrm{O}_{8}(6)$. Unless otherwise noted, all solutions were sparged with a constant supply of air in order to provide a source of agitation.

TABLE I. Compositions of AGR SIMFUEL pellets of different burn-ups

\begin{tabular}{ccc}
\hline Dopant & wt\% $\mathbf{2 5} \mathbf{~ G W d / t U}$ & $\mathbf{w t} \%$ in $\mathbf{4 3} \mathbf{~ G W d} / \mathbf{t U}$ \\
\hline $\mathrm{UO}_{2}$ & 95.705 & 92.748 \\
$\mathrm{Nd}_{2} \mathrm{O}_{3}$ & 0.761 & 1.284 \\
$\mathrm{ZrO}_{2}$ & 0.793 & 1.276 \\
$\mathrm{MoO}_{3}$ & 0.614 & 1.027 \\
$\mathrm{RuO}_{2}$ & 0.512 & 0.892 \\
$\mathrm{BaCo}_{3}$ & 0.328 & 0.576 \\
$\mathrm{CeO}_{2}$ & 0.297 & 0.499 \\
$\mathrm{PdO}_{2 O_{2} \mathrm{O}_{3}}$ & 0.195 & 0.425 \\
$\mathrm{La}_{2} \mathrm{O}_{3}$ & 0.080 & 0.115 \\
$\mathrm{SrO}$ & 0.156 & 0.256 \\
$\mathrm{Y}_{2} \mathrm{O}_{3}$ & 0.081 & 0.126 \\
$\mathrm{CsCO}_{3}$ & 0.095 & 0.149 \\
$\mathrm{TeO}_{2}$ & 0.311 & 0.495 \\
& 0.073 & 0.130 \\
\hline
\end{tabular}




\section{$\underline{\text { Results \& Discussion }}$}

Before discussing the Raman spectra of pure $\mathrm{UO}_{2}$ and SIMFUEL pellets, it is first informative to describe the $\mathrm{UO}_{2}$ fluorite lattice structure and its capacity for accommodating excess oxygen anions. Stoichiometric crystalline $\mathrm{UO}_{2}$ is isostructural with cubic fluorite $\left(\mathrm{CaF}_{2}\right)$. Each unit cell consists of four $\mathrm{U}$ ions sitting on a face centered cubic (fcc) sublattice and eight $\mathrm{O}^{2-}$ ions forming a cubic sublattice embedded in the $\mathrm{U}^{4+}$ sublattice (7). This structure is shown schematically in Figure 2.

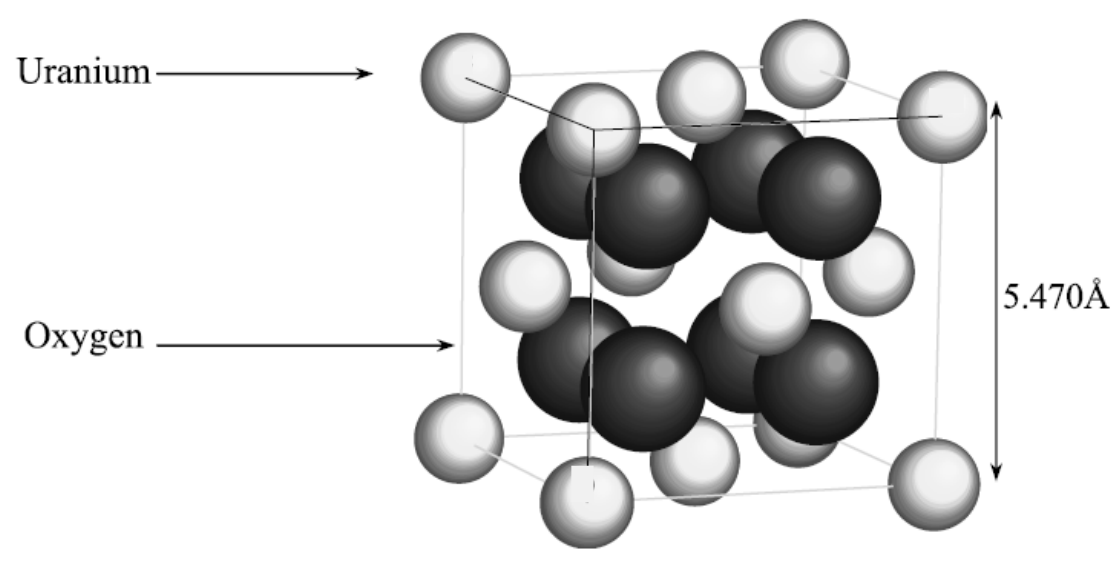

Figure 2. Schematic representing cubic fluorite structure of $\mathrm{UO}_{2}$ lattice (8)

The fluorite structure of $\mathrm{UO}_{2}$ is able to generate a number of derivative structures. This flexibility to generate derivative structures exists due the presence of octahedral vacancies at the centre of the unit cell and its capacity to accommodate excess anions. Insertion of $\mathrm{O}$ into an interstitial site (i) within the $\mathrm{UO}_{2}$ lattice leads to the formation of point defects within a retained fluorite structure of overall stoichiometry $\mathrm{UO}_{2+\mathrm{x}}$. Upon the introduction of further $\mathrm{O}_{i}$ into interstitial sites, the concentration of point defects increases and the fluorite structure becomes more distressed, giving rise to more widespread structural rearrangements and leading to extended defect structures. The generation of these extended defect structures displaces oxygen atoms from the lattice sites that are adjacent to the interstitial sites leading to the creation of additional lattice vacancies (7).

Micro-Raman spectroscopy is a particularly useful technique for studying such defect structures as it is sensitive to small distortions of the $O$ sub-lattice (9). However, before studying the occurrence of such defect structures in AGR SIMFUELs and the effect that their presence may have on the susceptibility of the SIMFUEL's surface to reaction with hydrogen peroxide, it is useful to briefly consider the behaviour of undoped $\mathrm{UO}_{2}$ samples as a baseline. Thus, Figure 3 shows spectra recorded from: (a) an as-received undoped $\mathrm{UO}_{2}$ pellet, (b) an undoped $\mathrm{UO}_{2}$ pellet exposed to oxygenated water for 1 hour and (c) an undoped $\mathrm{UO}_{2}$ pellet exposed to $100 \mu \mathrm{mol} \mathrm{dm}{ }^{-3} \mathrm{H}_{2} \mathrm{O}_{2}$ for one hour. 


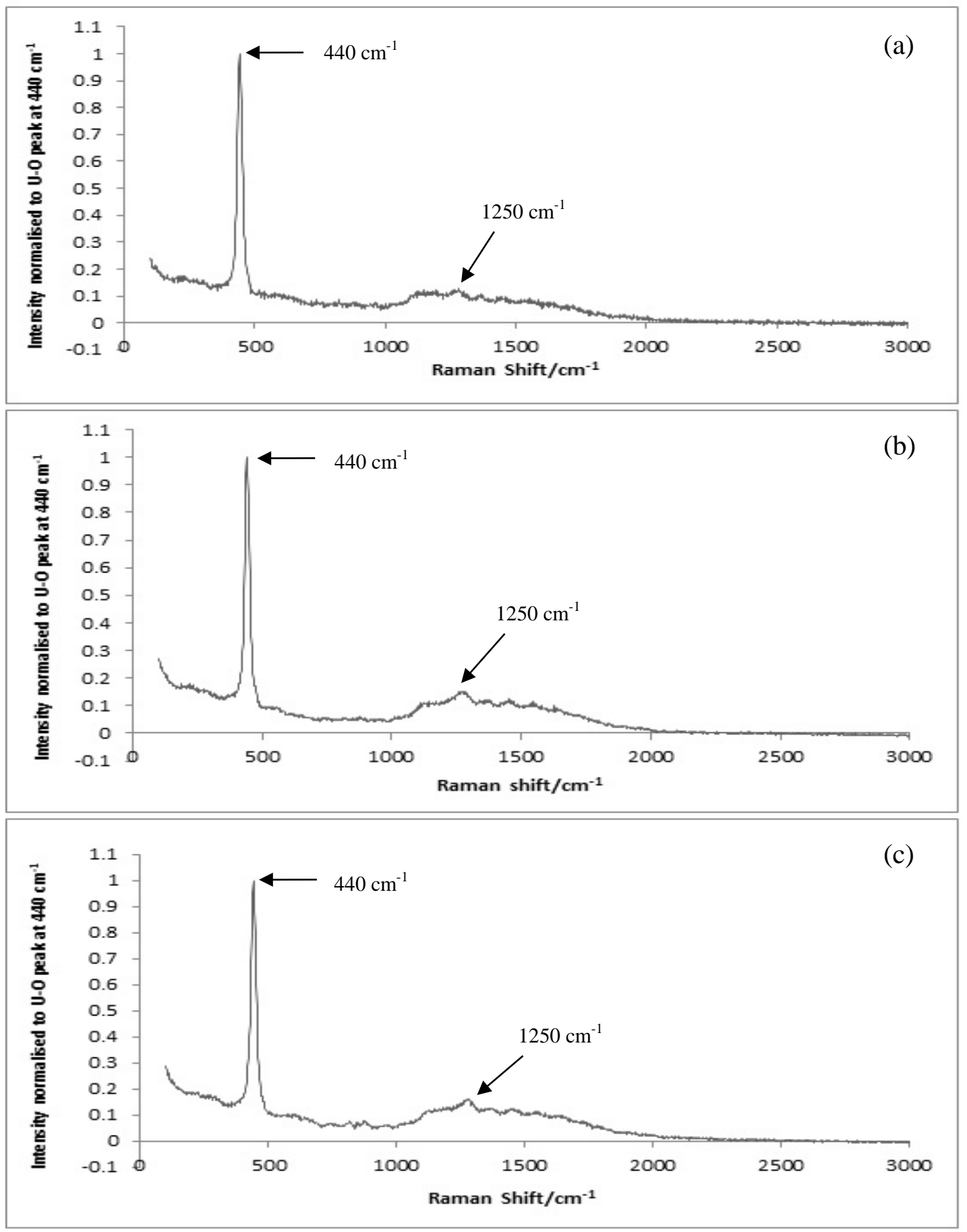

Figure 3. Micro-Raman spectra of an undoped $\mathrm{UO}_{2}$ sample: (a) as received; and after $1 \mathrm{~h}$ exposure to (b) oxygenated water and (c) $100 \mu \mathrm{mol} \mathrm{dm}{ }^{-3} \mathrm{H}_{2} \mathrm{O}_{2}$

From Figure 3 it can be seen that two bands are common across all three spectra. The dominant band at $440 \mathrm{~cm}^{-1}$ is associated with the fundamental U-O stretch of the cubic fluorite structure (4). Given its intensity, all spectra have been normalised with respect to this peak. The less intense, broad peak centered at $1250 \mathrm{~cm}^{-1}$ is a longitudinal optical (LO) phonon band and is therefore sensitive to lattice distortions (4). The absence of any shoulder intensity at $470 \mathrm{~cm}^{-1}$ suggests the absence of any developed tetragonal structure 
and that the local structure is still predominantly cubic (4). Treatment of an undoped $\mathrm{UO}_{2}$ pellet with oxygenated water and then $100 \mu \mathrm{mol} \mathrm{dm}{ }^{-3} \mathrm{H}_{2} \mathrm{O}_{2}$, Figures 3b \& c, show no significant change in intensity in the LO phonon band relative to the peak at $440 \mathrm{~cm}^{-1}$. This suggests that the washings are not changing the surface of the $\mathrm{UO}_{2}$ sample, as a change in surface structure, and particularly associated crystallinity, would manifest itself in a change in the LO phonon band intensity, widely considered to be a fingerprint of the fluorite structure (4).
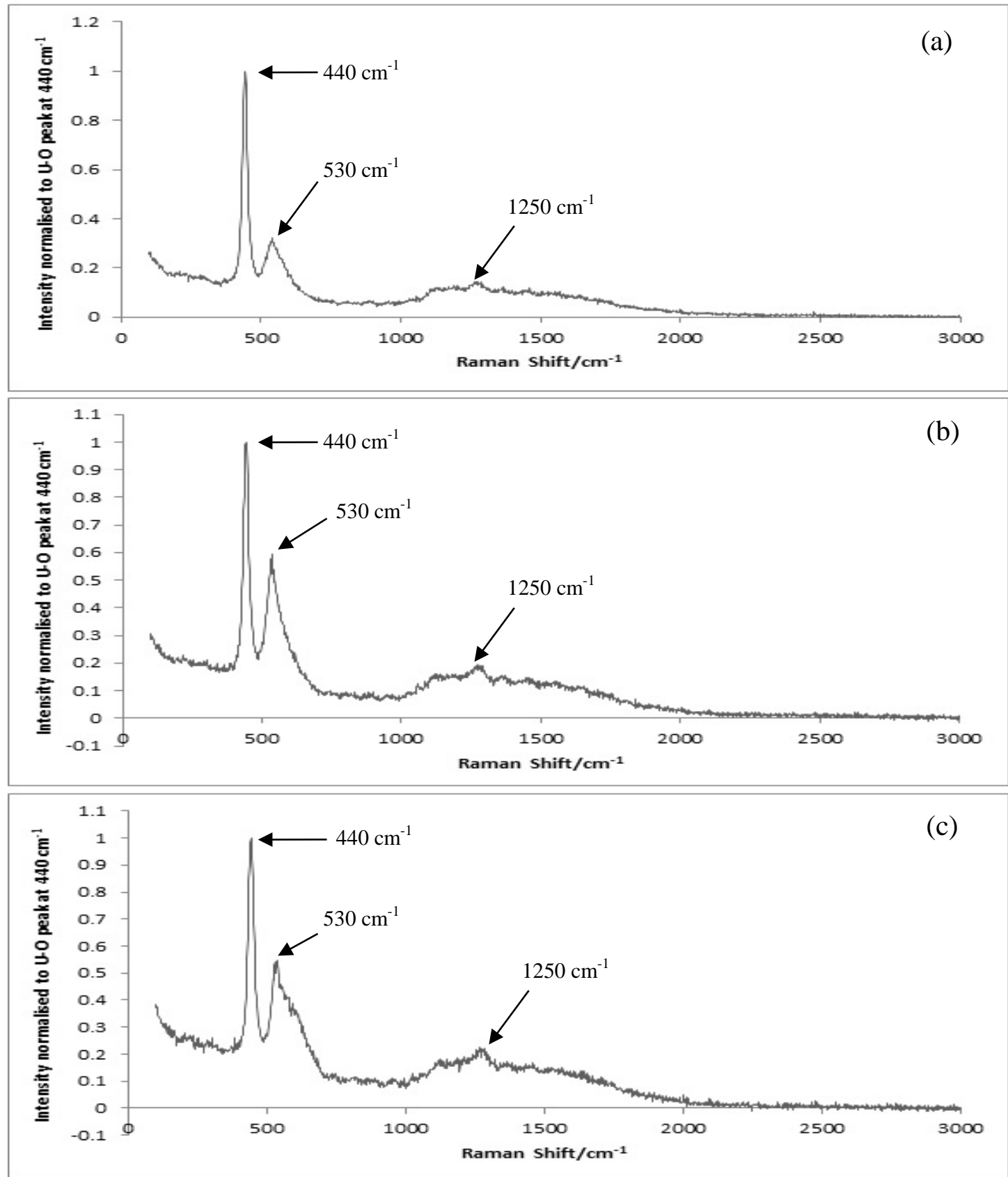

Figure 4. Micro-Raman spectra of a 25 GWd/tU SIMFUEL sample: (a) as received; and after $1 \mathrm{~h}$ exposure to (b) oxygenated water and (c) $100 \mu \mathrm{mol} \mathrm{dm}{ }^{-3} \mathrm{H}_{2} \mathrm{O}_{2}$ 
Consider now the Raman spectra of an AGR SIMFUEL sample with a composition equivalent to $25 \mathrm{GWd} / \mathrm{tU}$ burn-up. Figure 4 shows spectra recorded from: (a) an asreceived $25 \mathrm{GWd} / \mathrm{tU}$ SIMFUEL pellet, (b) a $25 \mathrm{GWd} / \mathrm{tU}$ SIMFUEL pellet exposed to oxygenated water for 1 hour and (c) a 25 GWd/tU SIMFUEL pellet exposed to $100 \mu \mathrm{mol}$ $\mathrm{dm}^{-3} \mathrm{H}_{2} \mathrm{O}_{2}$ for one hour. Consistent with Figure 3, these spectra have again been normalised using the peak at $440 \mathrm{~cm}^{-1}$ as reference.

As with the undoped $\mathrm{UO}_{2}$ sample of Figure 3, both the fundamental U-O stretch at $440 \mathrm{~cm}^{-1}$ and the L-O phonon band at $1250 \mathrm{~cm}^{-1}$ are apparent in the spectra of the asreceived sample of Figure 4a. However, a new band is observed between $470-600 \mathrm{~cm}^{-1}$. Such a feature has been previously reported by He and Shoesmith (9) in studies of PWR SIMFUELs and is indicative of lattice distortions as a result of dopant incorporation (simulating burn-up) and their associated oxygen vacancies (4). Using PWR SIMFUELs, Park et al. have shown that the introduction of dopants may result in increased defect clustering, producing a lattice contraction that can be observed by XRD (10). When the $25 \mathrm{GWd} / \mathrm{tU}$ SIMFUEL pellet is exposed to water for $1 \mathrm{~h}$, Figure $4 \mathrm{~b}$, there is an increase in the intensity of the lattice damage peak between $470-600 \mathrm{~cm}^{-1}$. The effect of this lattice distortion is also apparent in the $1250 \mathrm{~cm}^{-1}$ phonon band, whose intensity relative to the reference peak at $440 \mathrm{~cm}^{-1}$ has decreased compared to the as-received sample of Figure 4a, indicating deviation from a perfect cubic-fluorite structure.

Looking at the spectra of the $\mathrm{H}_{2} \mathrm{O}_{2}$-treated sample, Figure 4c, it can be seen that the lattice damage peak has broadened, indicative of lattice damage and not just point defects, indicating that the structure is advancing further away from a cubic fluorite structure.

This is consistent with corrosion of the surface of the SIMFUEL sample, resulting in $\mathrm{O}_{i}$ introduction into the $\mathrm{UO}_{2}$ lattice via $\mathrm{U}(\mathrm{IV})$ oxidation, increasing the hyperstoichiometric character of the fuel matrix. However, as with the spectra of Figure 3, the lack of a shoulder at $470 \mathrm{~cm}^{-1}$ confirms that the structure is still predominantly cubic without the development of significant tetragonal character i.e. the $x$ value in $\mathrm{UO}_{2+x}$ does not yet exceed 0.15 . Finally, the absence of any peak in the region of $800-900 \mathrm{~cm}^{-1}$ indicates the absence of any uranyl ion bearing phases (4) in any of the samples studied in Figure 4, leading us to conclude that no detectable formation of studtite/metastudtite occurs as a result of either of the solution treatments of Figure 4.

Having described the general differences in the Raman spectra observed from undoped $\mathrm{UO}_{2}$ and AGR SIMFUEL simulating $25 \mathrm{GWd} / \mathrm{tU}$ burn-up, we now consider the Raman spectra of an AGR SIMFUEL with a larger simulated burn-up of $43 \mathrm{GWd} / \mathrm{tU}$ burn-up. Figure 5 shows spectra recorded from: (a) an as-received 43 GWd/tU SIMFUEL pellet, (b) a $43 \mathrm{GWd} / \mathrm{tU}$ SIMFUEL pellet exposed to oxygenated water for 1 hour and (c) a $43 \mathrm{GWd} / \mathrm{tU}$ SIMFUEL pellet exposed to $100 \mu \mathrm{mol} \mathrm{dm}{ }^{-3} \mathrm{H}_{2} \mathrm{O}_{2}$ for one hour. Consistent with Figure 3, these spectra have again been normalised using the peak at $440 \mathrm{~cm}^{-1}$ as reference.

Considering first the as-received sample of Figure 5a, a significant increase in the relative intensity (in relation to the reference peak at $440 \mathrm{~cm}^{-1}$ ) of the lattice damage peak at $470-600 \mathrm{~cm}^{-1}$ can be seen in comparison to the as-received sample of $25 \mathrm{GWd} / \mathrm{tU}$ burn-up, Figure 4a. This would be expected considering the higher concentration of dopants present as a result of higher simulated burn-up, as shown in Table I. However the 
water-treated and $\mathrm{H}_{2} \mathrm{O}_{2}$-treated spectra, Figures 5b \& c, show a decrease in intensity of the lattice damage peak when compared to the as-received sample, Figure 5a. Preliminary interpretation of this result suggests that it is consistent with the expected further addition of $\mathrm{O}_{i}$ to the matrix at the surface - driving a more distressed structure towards dissolution. In this case, treatment with peroxide is driving oxygen insertion and accompanying oxidation to the level that $x$ (i.e. $\mathrm{UO}_{2+x}$ ) attains values associated with matrix distribution as per the scheme shown in Figure 1. However, further work is required to confirm this analysis.

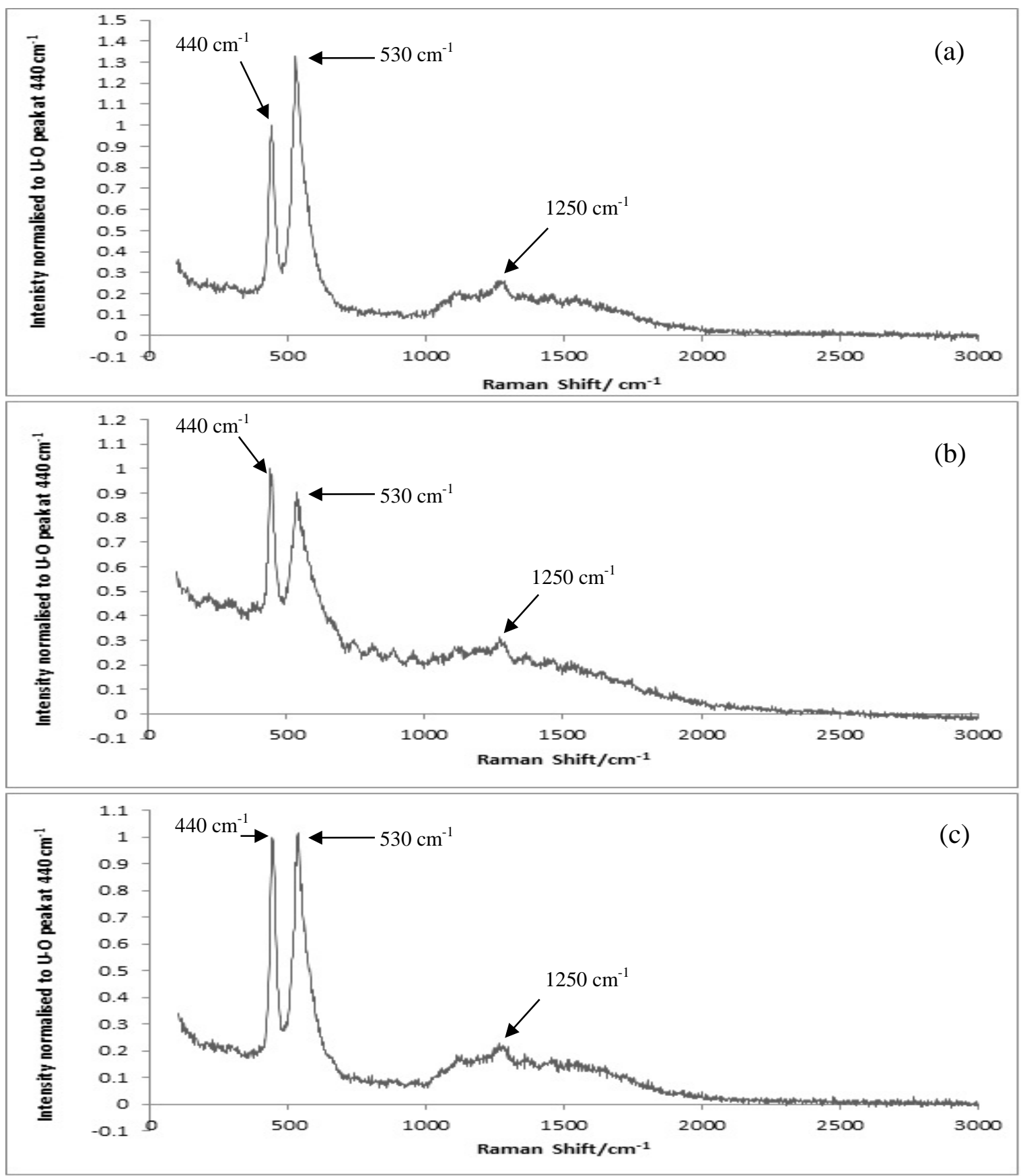

Figure 5. Micro-Raman spectra of a $43 \mathrm{GWd} / \mathrm{tU}$ SIMFUEL sample: (a) as received; and after 1 h exposure to (b) oxygenated water and (c) $100 \mu \mathrm{mol} \mathrm{dm}{ }^{-3} \mathrm{H}_{2} \mathrm{O}_{2}$ 
The spectrum of the water-treated sample of Figure 5b exhibits broadly similar results to those of Figure 5c, as well as showing an apparent increase in the relative intensity of the LO phonon band compared to Figure 5a. It is evident from the spectrum that there is a significant background signal in this spectrum, most likely attributable to surface roughness and reflectivity (11). However, as with previous samples, the absence of a readily discernible shoulder intensity at $470 \mathrm{~cm}^{-1}$ suggests that the structure is still predominantly cubic with no observable tetragonal character (4), although it is far from a perfect fluorite structure.

As with the $25 \mathrm{GWd} / \mathrm{tU}$ SIMFUEL sample there is no discernible peak in the range $800-900 \mathrm{~cm}^{-1}$ and so no evidence of uranyl-ion containing studtite formation at the surface due to $\mathrm{H}_{2} \mathrm{O}_{2}$ action. This may be due to the short exposure time of these samples to $\mathrm{H}_{2} \mathrm{O}_{2}$, and future studies will aim to leach samples for several hundred hours, in line with Amme et al. (12).

\section{Conclusions and Further Work}

AGR SIMFUELs at a range of simulated burn-ups have been prepared and the effect of the added dopants on the $\mathrm{UO}_{2}$ crystal structure has been investigated using microRaman spectroscopy. The effect of deliberately added $\mathrm{H}_{2} \mathrm{O}_{2}$ on the surface of simulated AGR fuels has also been studied using Raman.

Samples prepared in the absence of dopants exhibit the cubic fluorite structure expected of $\mathrm{UO}_{2}$ and show no change in their Raman spectra upon treatment with oxygenated water or solutions of aqueous hydrogen peroxide. A peak associated with lattice damage $\left(470-600 \mathrm{~cm}^{-1}\right)$ is observed from both 25 and $43 \mathrm{GWd} / \mathrm{tU}$ burn-up SIMFUEL, reflecting the introduction of dopant-associated lattice defects into the $\mathrm{H}_{2} \mathrm{O}_{2}$ matrix. As might be expected, the peak intensity is greater for the $43 \mathrm{GWd} / \mathrm{tU}$ sample.

An increase in the lattice damage peak is observed when the $25 \mathrm{GWd} / \mathrm{tU}$ burn-up SIMFUEL is exposed to water and subsequently $\mathrm{H}_{2} \mathrm{O}_{2}$ for $1 \mathrm{~h}$, suggesting that the structure at the surface is becoming more distressed. This is consistent with additional point defects being established as the concentration of interstitial oxygen is increased in the lattice via $\mathrm{H}_{2} \mathrm{O}_{2}$ induced surface oxidation of the SIMFUEL.

Exposure of the $43 \mathrm{GWd} / \mathrm{tU}$ SIMFUEL to the same concentration of hydrogen peroxide results in a decrease in damage peak intensity, suggesting peroxide driven dissolution of defected structures is occurring. At no point in any of the current studies do we see any evidence of tetragonal structure formation. Further work will initially aim to characterise individual 'grey phases', areas of $\mathrm{BaZrO}_{3}$, within the SIMFUEL samples and analyse these using Micro-Raman spectroscopy. Samples will also be exposed to $\mathrm{H}_{2} \mathrm{O}_{2}$ for longer time periods ( $1000 \mathrm{hrs}$ ) in order to investigate studtite formation. 


\section{Acknowledgements}

We thank the Nuclear Decommissioning Authority (NDA), the EPSRC (Award No EP/I036400/1) and The Lloyd's Register Foundation (LRF) for financial support. LRF, a UK registered charity and sole shareholder of Lloyd's Register Group Ltd, invests in science, engineering and technology for public benefit, worldwide.

\section{References}

1. G. Sattonnay, C. Ardois, C. Corbel, J. F. Lucchini, M. -F. Barthe, F. Garrido, D. Gosset, J. Nuc. Mat., 1, 11 (2001)

2. C. Corbel, G. Sattonnay, S. Guilbert, F. Garrido, M. -F. Barthe, C. Jegou, J. Nuc. Mat., 348, 1 (2006)

3. B. E. Burakov, E. E. Strykanova, E. B. Anderson, Mater. Res. Soc. Symp. Proc., 465, 1309 (1997)

4. H. He, M. Broczkowski, K. O’Neil, D. Ofori, O. Semenikhim and D. Shoesmith, Western University Report, NWMO TR-2012-09, (2012)

5. R. F. Burstall, UK Atomic Energy Authority Report ND-R-328 (R) (1979)

6. G. T. Brett, Department of the Air Force, Air University Thesis, AFIT/GNE/ENP/05-01 (2005)

7. D.W. Shoesmith, S. Sunder, W. H. Hocking, in Electrochemistry of Novel Materials, J. Lipkowski and P. N. Ross, Editors, p. 297, VCH, New York (1994)

8. H. Idriss, Surface Science Reports, 65, 67 (2010)

9. H. He and D. Shoesmith, Phys. Chem. Chem. Phys. 12, 8108 (2010)

10. K. Park, and D.R. Olander, J. Nuc. Mat., 187, 89 (1992)

11. M.A. Beard, O.R Ghita, K.E. Evans, J. Raman Spectrosc., 42, 744 (2011)

12. M. Amme, B. Renker, B. Schmid, M. Feth, H. Bertagnolli, W. Döbelin, J. Nuc. Mat., 2-3, 202 (2002) 